Immunochemistry. Pergamon Press 1969. Vol. 6, pp. 751-755. Printed in Great Britain

\title{
STUDIES ON THE ANTIGENIC PROPERTIES OF THE Fd-FRAGMENT OF A HUMAN G-MYELOMA PROTEIN (DAW)
}

\author{
B. J. M. ZEGERS and R. E. BALLIEUX \\ Division of Immunochemistry, Department of Medicine, University Hospital, Utrecht, \\ The Netherlands
}

(First received 7 November 1968; in revised form 10 February 1969)

\begin{abstract}
The present investigation deals with an immunochemical approach in studies on the structure of Fd-fragments of human immunoglobulins. Rabbits were immunized with a preparation of Fd-fragment of a human G-myeloma protein (Daw) [1]. Detailed studies on the reactions of the rabbit antiserum with a panel of antigens demonstrated that antibodies were obtained against an idiotypic site on the Fd- or the Fab-fragment of the Daw immunoglobulin molecule. No antibodies against any common region of the Fd-fragment could be detected in immunodiffusion experiments with the antigens used, a finding confirmed by the outcome of various haemagglutinating experiments. Structural implications of these findings are discussed.
\end{abstract}

\section{INTRODUCTION}

Only limited successful studies have been carried out in the past on the antigenic structure of the Fd-fragment of human immunoglobulins. In general the results obtained suggest that the Fd-fragment itself is weakly antigenic [2]. Using Fd-fragment obtained from the Fab-fragment of pooled human IgG, Mul[3] was not able to produce in rabbits precipitating antibodies, specific for the Fd-fragment. In other studies it was found again extremely difficult to produce precipitating antibodies to the Fd-fragment of IgG by immunization of rabbits and guinea pigs with isolated $\gamma$-chains from pooled human IgG [4]. In contrast to this work on isolated Fd-fragments or heavy chains, it is rather easy to obtain antibodies in rabbits specific for the configurational antigenic structure, formed by the combination of $\mathrm{H}$-chains or Fd-fragments with L-chains [5-8]. Although the results of recent work on these configurational antigenic structures suggest that the Fd-fragment has antigenic class-specificity, and thus possesses an antigenic structure common to all (or many) immunoglobulins of a particular class or subclass, no direct evidence could be obtained [8]. In the present work another approach has been followed in which a Fd-preparation of a well studied G-myeloma protein (Daw) $[1,9,10]$ was used as an antigen. In this paper the results of a study on the antigenic properties of this Fd-fragment will be described.

\section{MATERIALS AND METHODS}

The myeloma globulin (Daw) was a $\mathrm{Gm}(1)$, type L, $7 S$ IgGI-protein. The isolated L-chains, the Fab, Fc and Fd-fragments, as well as the original Dawprotein itself were kindly supplied by Dr. E.M. Press, Cambridge. The preparation, isolation and properties of the various fragments of the Daw-protein are described elsewhere [1,9]. Due to the great similarity of the electrophoretic mobility of the Fab- and Fc-fragments, the Fab-fragment of the Daw-protein 
(referred to as $\mathrm{Fab}_{\text {Daw }}$ ) was contaminated with some Fc-fragment (referred to as $\mathrm{FC}_{\text {Daw }}$ ) and vice versa.

The Fab- and Fc-fragments from pooled normal IgG were obtained as described by Mul and Ballieux[8]. Heavy chains from pooled human IgG were isolated according to Fleischman et al. [11]. G-myeloma proteins were isolated by ammonium sulfate precipitation, followed by chromatography on DEAE cellulose with stepwise elution using $\mathrm{pH} 8.0$ phosphate buffers of increasing molarity. The Gm-typing of these purified myeloma proteins was performed by Dr. Erna van Loghem, who also kindly supplied twenty isolated G-myeloma globulins of known Gm-type.

The antiserum against the $\mathrm{Fd}_{\mathrm{Daw}}$-fragment was obtained in rabbits by footpad inoculation with a suspension of the protein in saline and Freund's adjuvant. About $0.5 \mathrm{mg}$ protein per rabbit was used. Serums from each bleeding were tested by immunoelectrophoresis and Ouchterlony analysis. Anti Gm-activity in the anti $\mathrm{Fd}_{\text {Daw }}$-antiserum was tested for by Dr. Erna van Loghem.

\section{RESULTS}

The development of antibodies in the anti $\mathrm{Fd}_{\text {Daw }}$-antiserum was initially tested in immunoelectrophoresis, with normal human serum being used as antigen. Precipitating antibodies to $\operatorname{IgG}$ were demonstrable two weeks after inoculation.

Analysis of the antiserum in immunodiffusion and immunoelectrophoresis with the various subunits and fragments of the Daw-protein demonstrated that the antiserum contained antibodies against $\mathrm{Fc}_{\text {Daw }}, \mathrm{Fab}_{\mathrm{Daw}}$ and the whole Dawprotein, but not against $L$-chains of the Daw-protein (Figs. I, 2(a, b)). In addition, the antiserum reacted with pooled $\operatorname{IgG}$ and with the Fc-fragment from pooled $\operatorname{IgG}$ but not with Fab from pooled IgG. No reaction was obtained in immunodiffusion experiments with the autologous Fd-fragment, probably because of the insolubility of this antigen. Due to the very limited amount of Fd-antigen available, absorption of the antiserum with the Fd-preparation could not be done. The results described so far are summarized in Table 1.

In Ouchterlony experiments a complete fusion of precipitin lines between $\mathrm{FC}_{\mathrm{Daw}}, \mathrm{FC}_{\mathrm{pow}}$ and pooled IgC was obtained (Figs. 2(a, b)). The antiserum therefore was not able to demonstrate specific structures in the $F c_{\text {Daw }}$. Moreover, no antigenic determinants except those present on the Fc-part of the $\gamma$-chains of pooled IgC could be distinguished. The Daw-protein showed spur formation over pooled IgG (Fig. 2(b)) suggesting that an antigenic structure specific for Daw-protein is not present in detectable concentration in normal $\operatorname{IgG}$. Since the

\begin{tabular}{llll}
$\begin{array}{l}\text { Table 1. Reaction of anti } \mathrm{Fd}_{\text {Daw }} \text {-antiserum } \\
\text { with antigens in immunodiffusion } \\
\text { immunoelectrophoresis }\end{array}$ \\
\hline $\mathrm{FC}_{\text {paw }}$ & + & $\mathrm{FC}_{\text {pool }}$ & + \\
$\mathrm{Fab}_{\text {Daw }}$ & + & $\operatorname{IgG}_{\text {pool }}$ & - \\
$\mathrm{IgG}_{\text {Daw }}$ & + & $\operatorname{IgG}_{\text {pool }}$ & + \\
$\mathrm{Fd}_{\text {Daw }}$ & - & & \\
$\mathrm{L}_{\text {Law }}$ & - & & \\
\hline
\end{tabular}




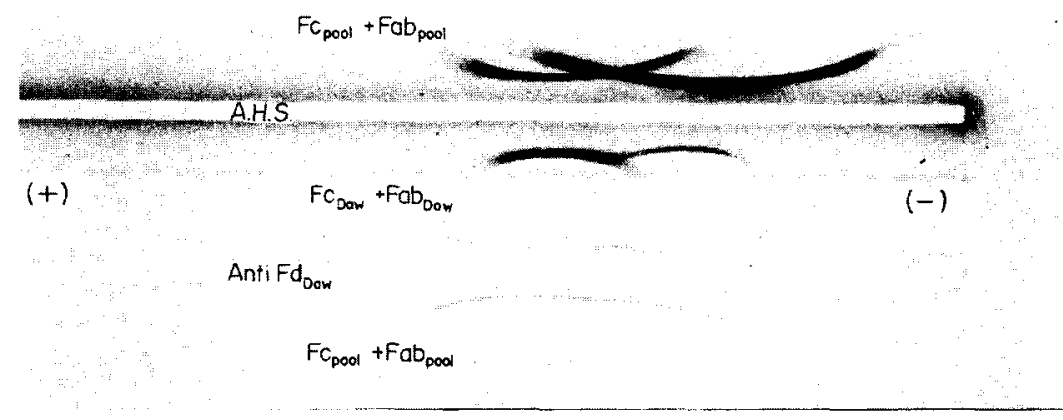

Fig. 1. Immunoelectrophoresis of $\mathrm{Fab}$ and $\mathrm{FC}$ from pooled human IgC (upper and lower well) and of Fab and Fc fragments from Daw (middle) using anti human antiserum (A.H.S. in upper reservoir) and anti $\mathrm{Fd}_{\text {Daw }}$ (lower). No reaction is obtained between Fab from pooled $\mathrm{IgG}$ and anti $\mathrm{Fd}_{\text {Daw }}$.

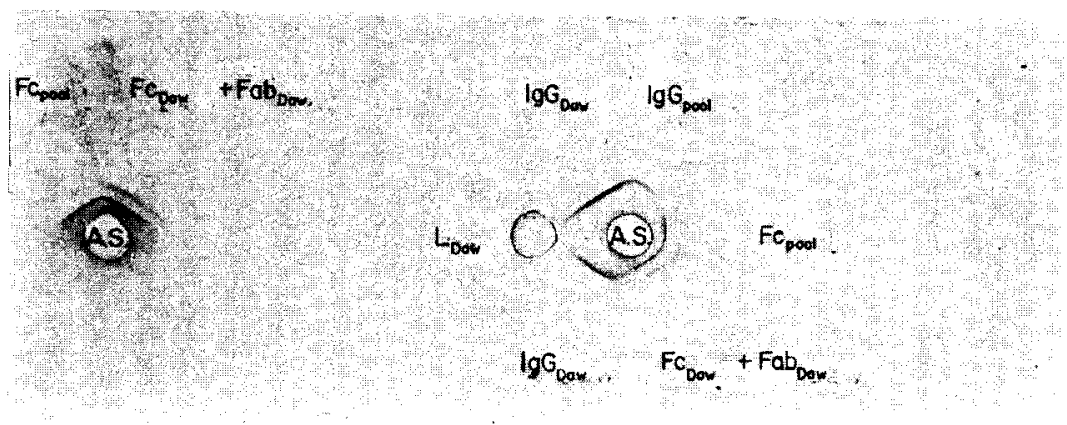

Fig. 2. Immunodiffusion of the anti $\mathrm{Fd}_{\text {Daw }}$ antiserum (A.S.) against several antigens. (a) FC from pooled IgG shows a reaction of identity with $\mathrm{FC}_{\text {Daw }}$. The second precipitation line is due to a reaction between the antiserum and $\mathrm{Fab}_{\text {Daw }}$ (b) Partial identity of $\mathrm{FC}_{\text {Daw }}$ and $\operatorname{Ig} \mathrm{C}_{\text {Daw }}$. Identity of $\mathrm{Fc}$ from pooled $\operatorname{IgG}, \mathrm{FC}_{\text {Daw }}$ and pooled IgG. Spurformation of IgG $\mathrm{C}_{\text {Daw }}$ over $\mathrm{F}_{\mathrm{C}_{\text {Daw }} \text {. Spurforma- }}$ tion of $\mathrm{IgG}_{\mathrm{Daw}}$ over pooled $\operatorname{IgG}$ is weak and therefore difficult to reproduce.

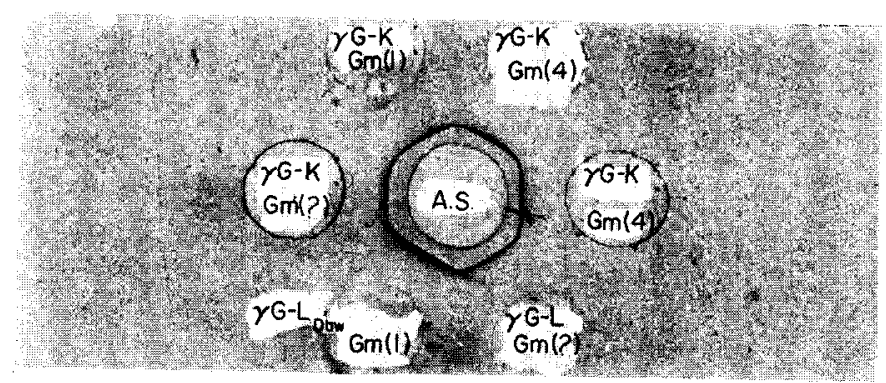

Fig. 3. Spurformation of $\operatorname{IgG} G_{\text {Daw }}$ over several myeloma proteins of type $K$ or type $\mathrm{L}$ and of different (im-types. 
$\mathrm{FC}_{\mathrm{Daw}}$ is not distinctive this specific structure must be localized in the Fabfragment of the Daw-protein. There is no precipitation reaction with L-chains from the Daw-protein. After absorption of the antiserum with Fc (from pooled IgG) only reactions with the Daw-protein and the $\mathrm{Fab}_{\text {Daw }}$-fragment were obtained. The reaction between the $\mathrm{Fab}_{\mathrm{Daw}}$ and the $\mathrm{Fd}_{\mathrm{Daw}}$-antiserum might be explained therefore by the presence of antibodies to the $\mathrm{Fd}_{\mathrm{Daw}}$-fragment directed against an antigenic site peculiar to Daw-Fd.

As mentioned already no precipitation reaction with Fab from pooled IgG was obtained. In addition no agglutinating antibodies against Fab from pooled IgG were demonstrated in haemagglutination experiments. It seems therefore that upon immunization with the $\mathrm{Fd}_{\mathrm{Daw}}$-preparation no antibodies directed against any invariable stretch of the Fd-fragment of IgG were obtained. The presence of antibodies against determinants on the common part of $\mathrm{Fd}$, blocked by L-chains in the intact Fab-or IgG-molecule, could be ruled out by testing the anti $\mathrm{Fd}_{\text {Daw }}$-antiserum with $\gamma$-chains from pooled normal IgG. A complete identity was observed in immunodiffusion experiments between $\gamma$-chains and Fcfragments. To study the possible relationship of the idiotypic specificity with Gm-factors, the antiserum was tested with 25 isolated G-myeloma proteins of various Gm-types and L-chain types. The Daw-protein showed spur formation with all G-myeloma globulins tested, while reactions of identity were obtained between these proteins (Fig. 3). This provides evidence that the anti $\mathrm{Fd}_{\text {Daw }^{-}}$ antiserum is not directed to Gm-factors, which is confirmed by the lack of anti $\mathrm{Gm}(\mathrm{z})$ activity shown by the anti $\mathrm{Fd}_{\text {Daw }}$-antiserum in various haemagglutination experiments. In addition, no antibodies specific for the combined heavy and light chains are present since type L G-myeloma proteins did not spur over type K G-myeloma proteins.

\section{DISCUSSION}

As was mentioned in the introduction, the study of the antigenicity of the Fd-fragment was directed towards the finding of an antigenic structure common to $\mathrm{Fd}$-fragments of $\mathrm{G}$-immunoglobulins. The results showed that immunization with the $\mathrm{Fd}_{\text {Daw }}$-preparation produced antibodies to the Fc-fragment of IgG and to Fabaw. The presence of antibodies to $\mathrm{FC}_{\mathrm{b}}$ may be explained by assuming that common structures are present in the Fd- and Fc-fragment of IgG. Although this possibility is highly interesting a more likely explanation in this case can be given. As mentioned in the section describing these antigens, the Fab- and FCfragment of the Daw-protein had very similar electrophoretic mobilities. The Fab-fragment therefore was contaminated with some Fc. In the isolation of the $\mathrm{Fd}_{\text {Daw }}$-fragment by gel filtration after reduction of the $\mathrm{Fab}_{\text {Daw }}$-fragment, some $\mathrm{FC}_{\text {Daw }}$ could easily have been eluted with the $\mathrm{Fd}_{\text {Daw }}$-fragment. The recognized high antigenicity of the Fc-fragment could explain the presence of antibodies to Fc-fragment in the antiserum prepared against the $\mathrm{Fd}_{\mathrm{Daw}}$-fragment. Unfortunately, lack of $\mathrm{Fd}_{\mathrm{Daw}}$-fragment makes it impossible to investigate the contamina-

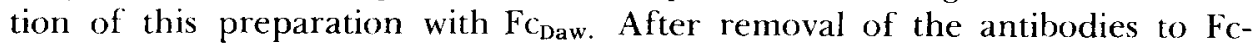
fragment by absorption with pure Fc from pooled IgG, only a reaction was left with the autologous $\mathrm{Fab}_{\text {Daw }}$-fragment. No antibodies to L-chains or to configurational antigen(s) common to most type L G-myeloma globulins $[3,8]$ could 
be detected. It might therefore be possible that the antiserum contained antibodies specific for the Fd-fragment of the Daw-protein. Although no direct evidence was obtained that the Fd-preparation was contaminated with trace amounts of Fab $_{\text {Daw }}$, it can not be ruled out that this idiotypic specificity was directed against a specific configurational antigenic structure on the Fab Daw $_{\text {Da }}$ This however is of limited interest since antibodies specific for the distinct structure of the Fab- or Fd-fragment of monoclonal proteins were frequently studied in the past $[12,13]$. It is on the other hand remarkable that after immunization with the $\mathrm{Fd}_{\mathrm{Daw}}$-fragment no precipitating or agglutinating antibodies directed against any common invariable stretch of the Fd-fragment could be demonstrated. This striking finding confirms the results obtained in earlier studies on Fdfragments [3] or heavy chains of human pooled IgG [4] and are in agreement with data obtained by Utsumi and Karush on rabbit Fd [20].

The outcome of the immunochemical studies is unexpected in view of the data obtained by chemical analysis. From comparative peptide mapping studies $[14,15]$ and from sequence studies on peptides containing the interchain and intrachain disulphide bridges of human G-myeloma globulins [16-19] it is apparent that the Fd-fragments, besides regions where the sequence varies from one molecule to another $\left(\mathrm{Fd}_{\mathrm{v}}\right)$, have regions where the amino acid sequence is common to all molecules $\left(\mathrm{Fd}_{\mathrm{c}}\right)$ of one particular class or subclass. As mentioned already antibodies to the distinct part of the $\mathrm{Fd}_{\text {Daw }}$ (or maybe $\mathrm{Fab}_{\text {Daw }}$ ) were obtained whereas the invariant stretch apparently showed lack of antigenicity. It has to be accepted therefore that the common sequence of the Fd-fragment of IgG is a poor antigen compared to the distinct part of $\mathrm{Fd}$ (or to the peculiar configurational Fab-antigens).

An explanation of this weak antigenicity of the common structure of the Fdfragment of IgG can not be given. To which extent antigenic competition between $\mathrm{Fd}_{\mathrm{v}}$ and $\mathrm{Fd}_{\mathrm{c}}$ is involved remains to be studied. The loss of antigenicity as a result of the isolation procedure has to be considered however. Mul[3] suggested that the apparent lack of antigenicity of $\mathrm{Fd}_{\mathrm{c}}$ may be explained by lack of speciesspecific antigenic determinants, resulting in tolerance in the rabbit.

The results discussed above are based on the study of only one isolated and purified homogeneous Fd-fragment. The significance of the findings will increase considerably if related work on well documented pure Fd-fragments of other G-myeloma globulins will be done. Since it is extremely difficult to obtain purified Fd-fragment of a large number of homogeneous G-globulins, the data obtained in this study might add to the little knowledge available on the antigenic properties of the Fd-fragment. The immunochemical findings however are intriguing in respect to the outcome of the structural studies in which common stretches in the Fd-fragment were well established, although the length and location remains to be determined.

Acknowledgements-The authors are very much indebted to Miss E.M. Press for helpful comments and for supplying the Fd-fragments and other subunits and fragments from the Daw-protein. Thanks are also due to Mrs. Caroline W. Easley for kindly correcting the manuscript and to Dr. Erna van Loghem for supplying myeloma proteins and testing antisera. 


\section{REFERENCES}

1. Press E. M., Piggot P. J. and Porter R. R., Biochem. J. 99, 356 (1966).

2. Kunkel H. G., Grey H. M. and Solomon A., Immunopathology (Edited by Grabar P. and Miescher P. A.), p. 220. Schwabe, Basel, Stuttgart (1965).

3. Mul N. A. J., Ph.D. Thesis, University of Utrecht (1968).

4. Zegers B. J. M., Wolters-Dicke H., Mul N. A. J. and Ballieux R. E., Proc. 8th Meet. Dutch Fedn Soc., Groningen (1967).

5. Prendergast R. A., Grey H. M. and Kunkel H. G., J. exp. Med. 124, 185 (1966).

6. Seligmann M., Mihaesco C. and Meshaka G., Science 154, 790 (1966).

7. Korngold L. and Madalinski K., Immunochemistry 4, 353 (1967).

8. Mul N. A. J. and Ballieux R. E., Immunochemistry 5, 339 (1968).

9. Piggot P. J. and Press F. M., Biochem. J. 104, 616 (1967).

10. Press E. M., Biochem.J. 104, 30c (1967).

11. Fleischman J. B., Pain R. H. and Porter R. R., Arch. Biochem. Suppl. 1, 174 (1962).

12. Grey H. M., Mannik M. and Kunkel H. G., J.exp. Med. 121, 561 (1965).

13. Seligmann M. and Mihaesco C., Gamma globulins. Structure and Control of Biosynthesis (Edited by Killander J.), p. 169. Almqvist and Wiksell, Stockholm (1967).

14. Frangione B. and Franklin E. C., J.exp. Med. 122, 1 (1965).

15. Frangione B., Prelli F. and Franklin E. C., Immunochemistry 4, 95 (1967).

16. Pink J. R. L. and Milstein C., Nature, Lond. 214, 92 (1967).

17. Frangione B. and Milstein C., Nature, Lond. 216, 939 (1967).

18. Pink J. R. L. and Milstein C., Nature, Lond. 216, 941 (1967).

19. Frangione B. and Milstein C., Abstr 5th Meet. Fedn Eur. biochem. Soc., p. 77, Prague (1968).

20. Utsumi S. and Karush F., Biochemistry 6, 2313 (1967). 